RESEARCH ARTICLE

\title{
Disguised Blessings amid Covid-19: Opportunities and Challenges for South African University Students with Learning Disabilities
}

\author{
Ndakaitei Manase ${ }^{\mathrm{i}}$
}

\begin{abstract}
The Covid-19 pandemic has led to changes from traditional face-to-face teaching and learning to online systems. These changes have resulted in a concerted focus by local and international scholars on how some students are disadvantaged from accessing pedagogy due to a lack of resources and supportive living conditions that enable meaningful off-campus learning. Simultaneously, disabilities in higher education is getting international attention, too, highlighting how students with disabilities are vulnerable to further exclusions and mental health problems. This article focuses on the pedagogical arrangements during the Covid-19 pandemic and the challenges and opportunities associated with online and remote learning for university students with learning disabilities. The article draws on the narratives of fifteen students with learning disabilities from a university in South Africa. An analysis of students' narratives within the Capability Approach's concept of conversion factors revealed how circumstances could enable or constrain students' abilities to achieve what they value in higher education. Students' narratives show that they engage better with online and remote learning despite some notable challenges. In conclusion, the pedagogical arrangements aimed at alleviating the disruptions caused by the Covid-19 pandemic can address the unmet educational needs of students with learning disabilities even though they have to overcome specific barriers.
\end{abstract}

\section{Keywords}

Capability Approach; conversion factors; Covid-19; learning disabilities; online learning; student affairs; university students with special needs

\section{Introduction}

The Covid-19 pandemic brought considerable changes to the higher education system that required unconventional responses (Adnan \& Anwar, 2020), such as online and remote learning. These responses rely on technology, which many universities, students, and lecturers in South Africa were not prepared for (Mhlanga \& Moloi, 2020). Overall, debates on Covid-19 and education attend more to challenges and inequalities that disadvantage students from accessing digital pedagogy within online learning. This article draws insights from students with learning disabilities' narratives to highlight both the challenges and opportunities of online learning during the Covid-19 pandemic. 
The literature on the Covid-19 experiences of students with disabilities, although scarce, discusses their mental health. Zhang et al. (2020) established that students with disabilities are affected by isolation and loneliness during the lockdown. Prolonged isolation can cause stress, anxiety, and depression (Galea et al., 2020; Benke et al., 2020), forcing students to turn to social media (Mahlaba, 2020). Asuncion et al. (2012) established that students with disabilities spend at least double the time on social media than on academic work, thus exhausting resources on non-academic activities and increasing the risk of depression and anxiety, as noted by Dobson-Lohman and Potcovaru (2020). While any student can face these challenges, those with disabilities are more susceptible to periodic acute depression and anxiety because of pre-existing conditions (Zhang et al., 2020).

\section{Online Learning for Students with Disabilities}

Online learning, which involves students' virtual participation in academic activities, offers students some degree of control over the time, place, path, or pace of learning (Hashey \& Stahl, 2014). Students can self-manage, plan, deliver and track their learning process (Almaiah et al., 2020).Various students with learning disabilities find online learning flexible (Crespo, 2020), hence suiting their academic needs. Flexible learning conditions require self-directed learners who are autonomous, responsible, show initiative in formulating and assessing their learning goals and requirements, and adopting strategies to attain goals or achieve expected learning outcomes (Mahlaba, 2020; Knowles, 1975). Students with learning disabilities might not have the same kind of control over the learning process because of difficulties with time management, problem-solving, and planning (Lee Booksh et al., 2010) - common clinical symptoms of learning disabilities. Hence, online and remote learning might not suit some of them.

Furthermore, Roberts, Crittenden and Crittenden (2011) suggest that students with learning disabilities are less likely to succeed in online learning where their disabilities interfere with accessibility and usability. Students who require accessible instructional technology such as screen-readers, can be disadvantaged if it is not available (Hashey \& Stahl, 2014). Cluttered learning content can be inaccessible to students with learning disabilities (Burgstahler, 2015), and thus they can be marginalised in online learning platforms. This subject matter becomes pertinent as the online method has become the norm owing to the Covid-19 pandemic.

\section{A Capability Approach to Understanding Students' Learning Experiences}

The Capability Approach developed by Amartya Sen (1999) accounts for individual real freedoms (capabilities), well-being ("the wellness of a person's state of being”) (Sen, 1993, p.36), and the achievement of what people have reason to value (Robeyns, 2017). Therefore, the Capability Approach is useful in examining conversion factors that affect how people function towards achieving what they value.

Conversion factors concern one's ability to transform resources or opportunities into achievements (Robeyns, 2017). These factors can be personal, social, and environmental (Robeyns, 2017) and, for students, encompass resilience or external factors such as learning 
conditions and disability policies. The conversion factors associated with online learning determine how circumstances affect what students value to achieve. Students in this study reported that they appreciate passing and having a qualification that opens up economic opportunities. Students' experiences are thus analysed to determine how they converted online learning engagements towards attaining a qualification they value as instrumental in getting employment.

\section{Methodology}

Narratives of fifteen full-time students who registered a learning disability with the University of the Free State, South Africa, were gathered through semi-structured interviews. Research participants were recruited using a combination of snowballing and convenience techniques because participants were difficult to get. Data was collected in 2019 for a broader Ph.D. study on the university experiences of students with learning disabilities. This data is useful in highlighting the challenges students experience in face-to-face classes to form the basis for arguments on whether online learning created opportunities for them. Four participants who were still studying in 2020 were contacted telephonically to follow up on how they experienced learning while working online and off the university campus during the Covid-19 pandemic. The study adopts a narrative inquiry research design (Polkinghorne, 1995), which is a qualitative research method involving first-hand accounts of experiences (Rudrum, 2005) focused on a particular population, in particular, social circumstances at a specific time (Riessman, 2008). Data were analysed descriptively to give a clear understanding of how online and remote teaching affected students. The emphasis is not on exhaustive personal life stories (Ball et al., 2013) but on the themes that focus on learning experiences during the Covid-19 pandemic. Therefore, the article seeks to answer the question: "How does online learning instituted during the Covid-19 pandemic affect students with learning disabilities?”

\section{Learning Experiences as Narrated by Students with Learning Disabilities}

Narrated accounts of students' learning experiences reveal difficulties in conventional classes as conditions are often unsupportive. Learning disabilities are invisible (Schabmann et al., 2020), and the symptoms are not typical of what many are accustomed to concerning disability. Students reported that they often devise ways of accessing and understanding learning content. One student with $\mathrm{ADHD}^{1}$ complained that: "There is nothing done for people like me in class. You have to find ways to make it work." ADHD can cause poor concentration, inattention, hyperactivity, high distractibility levels, and severe body impulsivity (Daley \& Birchwood, 2010). A student with ADHD can have trouble sustaining attention for long periods or experience difficulties following instructions, especially under pressure, even when one understands the instructions (Lee Booksh et al., 2010). Therefore, there is a need for alternative learning settings for such students.

1 Classified as a learning disability under the South African Higher Education Disability Services Association coding framework and the National Student Financial Aid Scheme disability policy. 
Nonetheless, these students have to attend face-to-face lectures and write tests and examinations on a stipulated date and time. Learning is expected to continue regardless of episodic flare-ups of adverse symptoms of ADHD as described below:

I have one or two days where I get very depressed and go through a mental shutdown that I don't have control over. During that time, I can't focus on my studies. I just go to the lecture for the sake of it. $(\mathrm{Liz})^{2}$

The above challenge can be overcome if students have options to access classes. It would help students if online learning accommodations ${ }^{3}$ form part of the university's disability support services. Unfortunately, students with learning disabilities are often denied online learning accommodations (Crespo, 2020; Barnard-Brak \& Sulak, 2010). The flexibility in accessing instruction in remote learning allows students with emotional difficulties to choose a suitable time to study and a convenient date to submit assignments.

Furthermore, the attention challenges and high levels of distractibility noted in Daley and Birchwood (2010) which affect students with ADHD are represented in participants' stories. Overcrowded classes, a reality at many universities in South Africa due to higher education's massification (Allais, 2014), compound students' difficulties. The description below is telling:

My attention is very bad such that if someone just clicks a pen, my attention goes there, then I stop listening to the lecturer. If it happens 3-4 times, I lose all attention. ... My first year was incredibly tough because we were 800 students in some classes. Students were sitting on the floor and some on the steps. It was very bad for my attention. It felt like time wasted to attend a lecture because, at the end of the day, you ask yourself, "What did I get out of that lecture?" Sadly, you can't really point at anything. (Frank)

Complexities between external and intrinsic conditions where learning conditions exacerbate learning disabilities are apparent in students' stories, as noted above. Personal and environmental factors intersect to disadvantage students with learning disabilities. A further example involves busy lecture schedules that can cause sensory overload (Kong \& Maha, 2019) and undermine students with learning disabilities' class engagement. Students expressed frustrations with long lectures through statements such as, "I lose interest after some time", "My mind shuts down after 45 minutes into the lecture," and "I end up hearing only sounds, not the actual words of a lecturer." Therefore, some lecture schedules can be restrictive for students with learning disabilities whose attention span is short. Yet, students still attend classes and contend with these limiting learning conditions.

Also, students with dyslexia raised complaints about fast-paced lectures. Of concern is lecturers' lack of skills to adapt teaching methodologies such that they accommodate the information processing needs and learning styles of students with dyslexia. Students complained about transmissionist teaching methods, as indicated in this excerpt:

2 Participant names are pseudonyms.

3 Disability accommodations are adjustments to curricular, instructional and physical settings for students with disabilities to fully-participate in higher education (Barnard-Brak \& Sulak, 2010). 
It's tough with dyslexia to understand when the lecturer is teaching fast. There's too much information given out in class. Most of the time, I am lost. I don't hear [understand] anything (Brenda)

The auditory perception and visual processing disorders that cause difficulties in making sense of sounds (Kelly, 2018) pose challenges for students with dyslexia in understanding taught content. Non-engaging teaching methods can be problematic for such students. As such, students' learning abilities can be affected negatively, as described by Brenda above.

Furthermore, this study revealed that sit-in and hand-written tests and examinations are not an ideal assessment presentation for them. Some students struggle to finish tests on time due to slow reading and writing speeds and difficulties expressing ideas on paper, common symptoms of dyslexia (Lewandowski et al., 2013). The degree of complexity varies, but students in this study acknowledged that they hardly pass when they write examinations at traditional venues because the conditions do not support the full display of their intellectual abilities. As such, students sought and received accommodations where they get extra time, separate sound-proof exam venues, and scribes to read and write for others.

Even though students reported benefits from these arrangements, the separate provisions pathologise learning disabilities and sustain students as disabled. For example, using a scribe to read and write for a student can create a sense of inadequacy in a student with a learning disability (Sainio et al., 2019). It can reinforce the idea that relying on someone else to write written exams is the only successful way of articulating exams. Alternative assessment modes (D'intino, 2017), such as online tests (with audible textreaders), can improve the accessibility and articulation of exams for students with reading and writing difficulties.

The above narrated learning experiences indicate that the set-up of learning spaces and teaching and assessment methodologies affect how students with learning disabilities engage with learning in face-to-face settings. Online and remote learning can be viewed positively for students with learning disabilities as it creates opportunities for students to learn without any worries associated with the conventional lecture method. Therefore, online-based assessments, which became mandatory after universities' closures, confirm this opportunity presented by the Covid-19 pandemic to create favourable assessment settings beneficial to most students with learning disabilities. Students also shared their experiences of online learning in the following section.

\section{Students' perspectives of online learning during the Covid-19 pandemic}

This article collected students with learning disabilities' experiences of learning during the Covid-19 pandemic. Follow-up telephonic calls were made with study participants who were still studying in 2020 as the Covid-19 pandemic unfolded. Discussion points included what was available to support online learning, what worked or not for students when working off-campus, challenges encountered in terms of resources and capacity, and any other ways online learning impacted their lives as university students. 
The narrated students' experiences indicated that they adapted well to online and remote learning. For example, students who already had proper technology, stable internet connections, technological skills, and family support sustained online learning. These students' resourcefulness before the Covid-19 pandemic positioned them at an advantage when they secured specialised computer software to aid with comprehension, spelling, and syntax. Others used dyslexia fonts and reading and writing enhancing software, which improves the accessibility, articulation, and quality of assignments. Dyslexia is associated with difficulties in the sequential naming of letters and words (Hall, McGregor \& Oleson, 2017), which can cause slow and weak reading fluency and poor comprehension of written text that necessitates assistive computer software. These arrangements support Wilde, Ryan, and Woodin's (2020) view that those with disabilities can straightforwardly become productive during the lockdown because most systems compel them to overcome obstacles and force them to be autonomous. Therefore, the level of the study participants allayed accessibility and competence challenges that Mukeredzi, Kokutse and Dell (2020) viewed as affecting students' engagement with online learning during the Covid-19 pandemic in South Africa. Students also reported no difficulties in locating learning resources on web-based sites, including accessing the university library resources while off the campus. The university continues to provide students with disabilities with extra time and extensions on submitting assignments as part of the disability accommodations. There are, therefore, indications that online learning suited most students with learning disabilities during the Covid-19 pandemic.

\section{Opportunities for learning online and remotely during the Covid-19 pandemic}

The less structured approach to learning created opportunities that suited most students with learning disabilities in this study. Students reported that learning online enabled them to engage well with their studies during the lockdown because there were few distractions compared to being in overcrowded classes that trigger severe anxiety and panic attacks. For example, one student with ADHD who appreciated the online learning arrangement stated that she "failed a test dismally" after writing in a "fully-packed exam hall" while on-campus. Others who struggle to learn in big-sized classes said that the online experience is less anxiety-inducing. Besides, students stated that online lecture content was low-datacompatible and thus shorter. Some appreciated online learning because there is access to learning material without any pressure to engage with it instantly, and there is unlimited access to recorded lectures. The following extracts capture the opportunities experienced by students with learning disabilities during online and remote learning:

I actually benefited a lot from learning online. ... Lecturers made PowerPoint slides with voice-overs, and then we could listen to them repeatedly while following the slides. What I liked is that lectures that normally take 2 hours in face-to-face classes ended up taking just 1 hour. To me, learning online was a better experience than face-to-face classes. (Sammy)

Learning online at home suited me very well. I study and work better with tests when there are no people around me. So, there was lots of working in my room and overnight when everyone was not around to call for my attention. So, I managed to do what needed to be done without anyone bothering me. (Tess) 
Online learning was also beneficial to students because they had to write assignments. Blackboard quizzes and self-marking tests that were less demanding than usual examinations. Students indicated that they prefer writing assignments to exams that usually require memorisation and good information retrieval skills, which many students with learning disabilities struggle with (Swanson \& Siegel, 2011). Thus, online assessments allowed students with learning disabilities to better integrate information better, unlike having to cram and retrieve information under pressure during the sit-in examinations. Brian, who has dyslexia, shared that replacing examinations with long assignments enabled him to perform very well and he had a 15\% increase on his average marks. With ADHD, Sammy experiences acute levels of test anxiety. She reported that she was "impressed by her marks" because online assessment methods were "friendly for her disability" as she could write when not feeling anxious, resulting in her achieving "impressive marks". Such accounts indicated some of the opportunities created by online learning for students with learning disabilities.

Students with learning disabilities often operate within rigid assessment systems (Tinklin, Riddell \& Wilson, 2004) that do not allow the full display of students' skills and capacity for learning. Limiting conditions usually cause discrepancies between students' intellectual potential and actual academic achievements (NILD, 2016). Therefore, the flexibility in Covid-19-initiated online learning allows variety and creativity in assessing students, which had positive effects on students' academic performances.

\section{Challenges associated with online and remote learning}

despite the opportunities created for students with learning disabilities through online learning, some faced challenges that affected their learning abilities (see the two narratives below). For example, the asynchronous learning approach, where students complete academic activities without direct contact with lectures (Smith \& Basham, 2014), pose some of these challenges. Firstly, the lack of student-lecturer interaction made it difficult for students to ask questions and get timely and adequate responses on academic issues of concern. These students mostly rely on and benefit from individual consultations with lecturers since some have information processing needs that affect their ability to understand the whole lecture at a given time. As confirmation two disabled students narrated how a lack of in-person teaching affected them:

In most cases, we got slides that we had to go through on our own. So it wasn't actually teaching. It affected my marks negatively. ... Sometimes, when I emailed a question, lecturers would answer it in a way they want to, without answering it satisfactorily. It was difficult to make a follow up because sometimes I got my response days after or the given answer confused me further. It is not the same as going to consult the lecturer in person, and I did not like online learning because of that. (Liz)

The only problem I had was that when you had a question, you couldn't ask it immediately I prefer to go physically and sit down with the lecturers and have them answer my questions. I didn't like emailing lecturers. It was very difficult for me to formulate my questions in an email. (Sammy) 
Liz's account exposes some lecturers' lack of skills in delivering teaching on online platforms or lack of commitment to changes in teaching modes. These challenges include lecturers who need to reach out to students and teach effectively online. The university where these students are based created an online platform with zero data rated where lecturers can present virtual classes with students so that they can chat and ask questions. Lecturers can also add audio descriptions on the PowerPoint slides to explain written text, upload videos of tutorials, and make learning content more interactive. PowerPoint with audio, however, is effective if the text and images are not distracting for students with attention difficulties or too cluttered for students with dyslexia to understand.

Students also noted that working on their computers all the time was distractive. Those with a short attention span reported that they ended up clicking on web pages that were not relevant to academic work and thus lost valuable time. The quotes below illustrate this point:

I was distracted working online at home. Now I was in front of the computer screen the whole time. I found myself clicking on new stuff and focusing on other things that pop-up instead of focusing on my assignments. (Brian)

I couldn't ignore social media. Even WhatsApp is on my laptop. I don't know, I needed that distraction while studying. The temptation of getting lost in social media was always there and it's funny how it felt like it's necessary. (Tess)

Online learning increased the students' risk of losing concentration by following nonacademic platforms. Students with ADHD who have low task vigilance (Ross \& Randolph, 2016) can lose total focus if they are distracted. Therefore, students risked losing interest in academic work where there was low motivation to learn or no strategies to self-regulate work habits (Ek \& Isaksson, 2013). These advantages and disadvantages of online learning are analysed next using the Capability Approach concept of conversion factors.

\section{Conversion Factors Associated with Online Learning for Students with Learning Disabilities}

In engaging analytically with the data, personal, environmental and social conversion factors were identified from students with learning disabilities' narrated experiences of learning online during the Covid-19 pandemic. The researcher analysed these intervening factors to determine their effect on students' conversion abilities that shape educational trajectories towards achieving suitable grades and qualifications they value.

\section{Personal conversion factors}

An inherent condition that affects a student's ability to focus on academic work or deficits that affect students' level of understanding lectures qualifies a learning disability as a personal conversion factor. A learning disability can thus pose the risk of diminishing the learning abilities of students. Students' pro-activeness in acquiring assistive software, being autonomous, resilient, and motivated to ensure that academic tasks are completed on time is evidence of their personal conversion factors. The effects of these characteristics were 
enabling, and enhanced students' ability to perform well and achieve valued educational outcomes. There are, therefore, individual personal conversion factors that affected students in different ways.

\section{Environmental conversion factors}

Environmental conversion factors are those associated with a university or home set-up (e.g. physical learning conditions, policies and practices). The study observed university arrangements that either diminish or expand students' capabilities before and after the Covid-19 pandemic. The over-crowded classes noted by students as distractive and anxietyinducing are environmental conversion factors that affected learning negatively. This study stated these factors as having a constraining effect on students' academic engagements. The home-working arrangement that some students, including Brian above, find challenging is also an environmental conversion factor. Working online all the time and spending resources on non-academic material has a potentially diminishing effect on students' efforts to achieve valued educational outcomes. However, having a home environment where students can learn when people who can distract them are out-of-reach, as narrated by Tess above, is an environmental conversion factor that contributed to students' academic success. The flexible assessment methods necessitated by online learning are also a conversion factor that positively affected students' academic performance. This was also confirmed by Sammy and Brian's narratives where students performed better than in usual assessment settings.

\section{Social conversion factors}

The research identified social conversion factors from the interaction students had with teaching staff. Sammy's and Liz's narratives reported the lack of student-lecturer interaction that made it difficult to ask questions and get immediate responses. Liz further indicated that she struggled to understand learning content because lecturers did not teach them properly in virtual classes. Therefore, the lack of face-to-face interaction, which limited students' access and understanding of content, risked underperformance for students with learning disabilities who rely mostly on individual consultations with lecturers for extra academic assistance. Limited direct access to lecturers affected students' ability to attain good marks, making it a social conversion factor that constrained students' capabilities.

\section{Conclusion and Recommendations}

This article explored the learning experiences of university students with learning disabilities, highlighting how the online learning arrangement affected their academic engagements. Insights from students suggest that online and remote learning during the Covid-19 university shutdown can support the needs of students with learning disabilities, despite some challenges. This article observes that remote learning offers students with learning disabilities opportunities to engage better with academic tasks, because some conditions under contact teaching limit their learning abilities. The researcher conceptualised students' learning experiences as opportunities and challenges, and identified conversion factors that interfered with students' abilities to achieve what they value in higher education. 
However, individual students are affected differently. Conditions that are advantageous to some can disadvantage others. The study supports the need for inclusive education systems that are not too restrictive for students to manage to learn. There is a need to diversify instructional material, teaching, and assessment modes, limiting disadvantages to students, particularly those with learning disabilities. The article recommends institutionalising the Universal Design for Learning (UDL) at universities to cater to all diversity forms. UDL involves designing learning spaces, the arrangement of physical environments, presentation of instruction, and assessment modes to be accessible and usable (without unique or separate support) by all students regardless of need (Dalton, 2020). UDL encourages the multiple means of representation of instruction and information, multiple means of learning engagement processes, and multiple means of expression by students in demonstrating their understanding of content (Smith \& Basham, 2014). Online learning, made compulsory by the Covid-19 pandemic, can fulfil these UDL principles because it allows multi-modal presentation and engagement with instruction.

\section{Acknowledgements}

I thank Drs Mikateko Mathebula and Faith Mukwananzi for their comments, the research participants for their cooperation, and greatly value my supervisors' mentoring during the main PhD study.

\section{Research Ethics}

This article is drawn from a $\mathrm{PhD}$ study with an ethical clearance number UFS-HSD2019/ 0038/2903 from the University of the Free State's General/Human Research Ethics Committee.

\section{Conflict of Interest}

None.

\section{Funding}

The PhD study is funded by the SARCHi Chair in Higher Education and Human Development, NRF grant number 86540.

\section{References}

Adnan, M. \& Anwar, K. (2020). Online learning amid the covid-19 pandemic: students' perspectives. Online Submission, 2(1), 45-51. https://doi.org/10.33902/JPSP.2020261309

Allais, S. (2014). A critical perspective on large class teaching: the political economy of massification and the sociology of knowledge. Higher Education, 67(6), 721-734. https://doi.org/10.1007/s10734-0139672-2

Almaiah, M.A., Al-Khasawneh, A. \& Althunibat, A. (2020). Exploring the critical challenges and factors influencing the e-learning system usage during Covid-19 pandemic. Education and Information Technologies, 1. https://doi.org/10.1007/s10639-020-10219-y

Ball, S., Macrae, S. \& Maguire, M. (2013). Choice, pathways and transitions post-16: New youth, new economies in the global city. Routledge. https://doi.org/10.4324/9781315043296 
Barnard-Brak, L. \& Sulak, T. (2010). Online versus face-to-face accommodations among college students with disabilities. The American. Journal of Distance Education, 24(2), 81-91. https://doi.org/10.1080/ 08923641003604251

Burgstahler, S. (2015). Opening doors or slamming them shut? Online learning practices and students with disabilities. Social Inclusion, 3(6), 69-79. https://doi.org/10.17645/si.v3i6.420

Crespo, I. (2020). Accessibility dissonance:The disability community's overlooked fight for remote learning. https://www.statepress.com/article/2020/04/spmagazine-accessibility-dissonance-the-disabilitycommunitys-overlooked-fight-for-remote-learning [Accessed 13 December 2020].

Daley, D. \& Birchwood, J. (2010). ADHD and academic performance: Why does ADHD impact on academic performance and what can be done to support ADHD children in the classroom? Child: care, health and development, 36(4), 455-464. https://doi.org/10.1111/j.1365-2214.2009.01046.x

Dalton, E.M. (2020). UDL and connected laws, theories, and frameworks. Universal Access Through Inclusive Instructional Design: International Perspectives on UDL, 3-16. https://doi.org/10.4324/9780429435515-1

D'intino, J.S. (2017). Learning disabilities in Canada: Definitions and accommodations. Canadian Psychology/psychologie canadienne, 58(3), 228. https://doi.org/10.1037/cap0000116

Ek, A. \& Isaksson, G. (2013). How adults with ADHD get engaged in and perform everyday activities. Scandinavian Journal of Occupational Therapy, 20(4), 282-291. https://doi.org/10.3109/11038128.20 13.799226

Galea, S., Merchant, R.M. \& Lurie, N. (2020). The mental health consequences of Covid-19 and physical distancing: The need for prevention and early intervention.JAMA internal medicine, 180(6), 817-818. https://doi.org/10.1001/jamainternmed.2020.1562

Hall, J., McGregor, K.K. \& Oleson, J. (2017). Weaknesses in lexical-semantic knowledge among college students with specific learning disabilities: Evidence from a semantic fluency task. Journal of Speech, Language, and Hearing Research, 60(3), 640-653. https://doi.org/10.1044/2016_JSLHR-L-15-0440

Hashey, A.I. \& Stahl, S. (2014). Making online learning accessible for students with disabilities. Teaching Exceptional Children, 46(5), 70-78. https://doi.org/10.1177/0040059914528329

Kelly, A. (2018). Working with adults with a learning disability. Routledge. https://doi.org/10.4324/9781 315172521

Knowles, M.S. (1975). Self-directed learning: A guide for learners and teachers. Association Press.

Kong, M. \& Maha, J. (2019). Sensory processing: shifting our mindset to improve care delivery. Pediatric research, 86(4), 544-545. https://doi.org/10.1038/s41390-019-0489-2

Lee Booksh, R., Pella, R.D., Singh, A.N. \& Drew Gouvier, W. (2010). Ability of college students to simulate ADHD on objective measures of attention. Journal of Attention Disorders, 13(4), 325-338. https://doi.org/10.1177/1087054708329927

Mahlaba, S.C. (2020). Reasons why self-directed learning is important in South African during the Covid-19 pandemic. South African Journal of Higher Education, 34(6), 120-136. https://doi.org/10.20 853/34-6-4192

Mhlanga, D. \& Moloi, T. (2020). Covid-19 and the digital transformation of education: What are we learning on 4IR in South Africa? Education Sciences, 10(7), 180. https://doi.org/10.3390/educsci 10070180

Mukeredzi, T, Kokutse, F. \& Dell, S. (2020, April 22). Student bodies say e-learning is unaffordable and elitist. University World News (Africa Edition). https://www.universityworldnews.com/post. php?story $=20200422075107312$ [Accessed 20 August 2020].

NILD (National Institute for Learning Development) (2016). What are the types of learning disabilities? http://nild.org/learning-disabilities/dyslexia-dysgraphia-dyscalculia/ [Accessed 9 May 2018]. 
Polkinghorne, D.E. (1995). Narrative configuration in qualitative analysis. International Journal of Qualitative Studies in Education, 8(1), 5-23. https://doi.org/10.1080/0951839950080103

Riessman, C.K. (2008). Narrative methods for the human sciences. Sage.

Roberts, J.B., Crittenden, L.A. \& Crittenden, J.C. (2011). Students with disabilities and online learning: A cross-institutional study of perceived satisfaction with accessibility compliance and services. The Internet and Higher Education, 14(4), 242-250. https://doi.org/10.1016/j.iheduc.2011.05.004

Robeyns, I. (2017). Wellbeing, freedom and social justice: The capability approach re-examined. Open Book Publishers. https://doi.org/10.11647/OBP.0130

Ross, P. \& Randolph, J. (2016). Differences between students with and without ADHD on task vigilance under conditions of distraction. Journal of Educational Research and Practice, 4(1), 1-10.

Rudrum, D. (2005). From narrative representation to narrative use: Towards the limits of definition. Narrative, 13(2), 195-204. https://doi.org/10.1353/nar.2005.0013

Sainio, P.J., Eklund, K.M., Ahonen, T.P. \& Kiuru, N.H. (2019). The role of learning difficulties in adolescents' academic emotions and academic achievement. Journal of learning disabilities, 52(4), 287-298. https://doi.org/10.1177/0022219419841567

Schabmann, A., Eichert, H.C., Schmidt, B.M., Hennes, A.K. \& Ramacher-Faasen, N. (2020). Knowledge, awareness of problems, and support: university instructors' perspectives on dyslexia in higher education. European Journal of Special Needs Education, 35(2), 273-282. https://doi.org/10.1080/088 56257.2019.1628339

Sen, A. (1993). Capability and wellbeing. The Quality of Life, 30. https://doi.org/10.1093/0198287976.0 03.0003

Sen,A. (1999). Development as freedom. Oxford University Press.

Smith, S.J. \& Basham, J.D. (2014). Designing online learning opportunities for students with disabilities. Teaching Exceptional Children, 46(5), 127-137. https://doi.org/10.1177/0040059914530102

Swanson, H.L. \& Siegel, L. (2011). Learning disabilities as a working memory deficit. Experimental Psychology, 49(1), 5-28.

Tinklin, T., Riddell, S. \& Wilson, A. (2004). Policy and provision for disabled students in higher education in Scotland and England: The current state of play. Studies in Higher Education, 29(5), 637-657. https://doi.org/10.1080/0307507042000261599

Wilde, A., Ryan, S. \& Woodin, S. (2020). Covid-19 and the academy. https://es.britsoc.co.uk/Covid-19and-the-academy/ [Accessed 22 May 2020.

Zhang, H., Nurius, P., Sefidgar, Y., Morris, M., Balasubramanian, S., Brown, J., Dey, A.K., Kuehn, K., Riskin, E., Xu, X. \& Mankoff,J. (2020). How does Covid-19 impact students with disabilities/health concerns? https://arxiv.org/abs/2005.05438

\section{How to cite:}

Manase, N. (2021). Disguised Blessings amid Covid-19: Opportunities and Challenges for South African University Students with Learning Disabilities. Journal of Student Affairs in Africa, 9(1), 107-118. DOI: $10.24085 /$ jsaa.v9i1.1431 